\title{
Viticulture for Sparkling Wine Production: A Review
}

\author{
Joanna E. Jones, ${ }^{1 *}$ Fiona L. Kerslake, ${ }^{1}$ Dugald C. Close,${ }^{1}$ \\ and Robert G. Dambergs ${ }^{1}$
}

\begin{abstract}
The current understanding of the influences of climate and viticultural practices on fruit quality at harvest and on sparkling wine quality is reviewed. Factors such as variety, clone, planting density, pruning method, local climate and soils, and current and future climate warming are discussed in the context of achieving a desired harvest quality. A common observation was the relatively less intensive viticultural management applied to grapes destined for sparkling wines compared to table wines throughout the world. Few studies have focused on management of fruit specifically for sparkling wine production. Given that it is accepted that a lower $\mathrm{pH}$, higher titratable acidity, and lower soluble sugars than table wine are considered desirable for sparkling wine production, the literature from viticultural studies for table wines which influence these desired fruit quality parameters has been reported. Specific findings on canopy management, leaf removal, and yield manipulation for the production of table wines indicate potential for application and development to optimize fruit for the production of sparkling wines. Fruit quality targets are remarkably uniform across international growing regions but distinct combinations of variety, clone, and management are currently used to arrive at those targets. Further, studies of viticultural management, particularly those that alter cluster temperature and exposure to incident light, yield manipulation, and fruit quality are likely to best inform production techniques that result in fruit quality ideal for the production of premium sparkling wines. New challenges include the need for increasing mechanization to maintain cost-effective production and climate warming, which affects the production of fruit for premium sparkling production in terms of flavor development and high acidity. Current trends include the diversification of growing regions to cooler regions that enable the production of high acid fruit and increased exploration of alternative varieties and clones that are better suited to a warmer climate.
\end{abstract}

Key words: sparkling wine, viticultural practices

Until the late 1600 s, French winemakers were still trying to rid their wines of the carbon dioxide bubbles created by the fermentation process that caused bottles to explode. Subsequently, a rise in preference for these sparkling wines by the British, and in particular royalty, led to the process of deliberately capturing bubbles for quality sparkling wine, which was primarily produced in the Champagne region of France (Robinson 2006). Over time, sparkling wine production has been introduced in many areas, including regions in Germany, Portugal, Spain, Italy, South Africa, North America, the United Kingdom, and Australia.

Winemaking techniques significantly influence sparkling wine style. Many processes can influence the structure and complexity of the finished wines, such as reduced phenolic extraction by whole bunch pressing, oxidative handling, fining, yeast strain selection, the development of other flavors such as those introduced by malolactic fermentation (MLF), use of oak, and time on lees for both base and tiraged wines (McKenzie 1994). These techniques are applied variously to produce a multitude of styles; however, far less is known

${ }^{1}$ Tasmanian Institute of Agriculture, School of Land and Food, University of Tasmania, Private Bag 98, Hobart, Tasmania, Australia, 7001.

*Corresponding author (Joanna.Jones@utas.edu.au)

Manuscript submitted Sept 2013, revised Jan 2014, Apr 2014, accepted Jul 2014

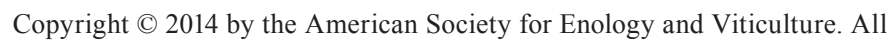
rights reserved.

doi: 10.5344/ajev.2014.13099 about practices that can be applied in the vineyard to target fruit quality for sparkling wine production.

In France the viticulture for producing Champagne is prescribed by the region, with aspects of varietal use, grapegrowing, wine production, and maturation regulated by the Appellation d'Origine Contrôlée (AOC) designation (Jackson 2008). Such is also the case for cavas, sparkling wines produced in some Spanish regions in which grape variety and yield are regulated (Pozo-Bayon et al. 2004). In other sparkling wine producing areas, such as cool-climate regions of Australia, management is not regulated and some vineyard managers make decisions about which blocks of fruit are destined for sparkling wine as late as veraison in the harvest year. Given the profound impact of seasonal variability on fruit quality, a viticultural program tailored to sparkling wine would be far more ideal. However, there are few published studies on the influence of vineyard management on the quality of sparkling wine, in contrast to the considerable research outlining the relationship between vineyard management and table wine quality (Pozo-Bayon et al. 2004). Sugar concentration, total acidity, and $\mathrm{pH}$ are the principal fruit quality criteria used for determining harvest dates for sparkling wine and, hence, wine quality (Hancock 1994). Sparkling wine production benefits from relatively low $\mathrm{pH}$, high titratable acidity, and low soluble sugars: knowledge of these parameters makes it possible to apply management strategies developed for the production of grapes grown for table wine to the production of grapes grown for sparkling wine. 
This review will investigate the available research on viticultural practices for producing high-quality sparkling wine, including that applicable from the table wine literature, highlight knowledge gaps and trends, and identify future research topics.

\section{Fruit Quality Goals for Sparkling Wine}

Fruit destined for sparkling wine production is generally harvested at a relatively low $\mathrm{pH}$, higher titratable acidity, and lower soluble sugars than fruit for table wine. In Champagne, harvest date is decided for each region by the National Institute of Appellation of Origin (INAO), which tracks maturity by sampling every three to four days. The desired maturity at the beginning of harvest is fruit that will produce $9 \%$ alcohol $(\mathrm{v} / \mathrm{v})$, and contain $12 \mathrm{~g} / \mathrm{L}$ tartaric acid for acidity and $\mathrm{pH}$ 2.9; however, these figures vary from year to year (Coppolani 1994). The targeted parameters are remarkably similar among regions that produce sparkling wine, including those specified in France, California, and Australia (Table 1). Fruit and juice flavor and aroma are also important considerations for harvest date, as achieving a desired style may not be possible if the juice is overtly varietal (Zoecklein 2002). Hancock (1994) suggested that ripe fruit flavors are required to give rise to complexity in sparkling wine, at $\sim 10$ to $11 \%(\mathrm{v} / \mathrm{v})$ alcohol, and that sugar concentration, total acidity, and $\mathrm{pH}$ are the principal criteria used for determining harvest date, with flavor, color (especially in red varieties), and cleanliness also key considerations.

Grapes for sparkling wine are typically harvested at lower sugar levels than grapes for table wines (Anderson et al. 2008a, Martinez-Lapuente et al. 2013). Coelho et al. (2009) observed that grapes picked at maturity, or one week after maturity, provided sparkling wines with the highest concentration of volatiles and that grapes picked earlier led to wines with more intense herbaceous notes. Zoecklein (2002) reported the fruit maturity of some California varieties for sparkling wine production based on averages across several viticultural regions (Table 1). As higher acid levels in fruit are desirable for sparkling wine production, greener flavors and aromas are preferred over riper fruit.

These fruit quality parameters for sparkling wine production can help growers to establish dedicated blocks and use specific management techniques in order to produce superior fruit for production of sparkling wines. Such considerations include grape variety, vine density and pruning, canopy management, climate and soil, and yield.

\section{Grape Variety}

Grape variety has been described as one of the three major factors influencing the character of bottle-fermented sparkling wines, together with vineyard location and yeast autolysis (de La Presa-Owens et al. 1998). Different sparkling wine producing regions use different grape varieties to produce their desired styles of sparkling wine (Table 2). In Champagne, the permitted varieties are restricted to Chardonnay, Pinot noir, Pinot Meunier, and the rarely used Petit Meslier and Arbanne (Coppolani 1994). Each of the three main varieties contribute individual attributes to the finished wines, described as "finesse and elegance" for Chardonnay, "body" for Pinot noir, and "fruitiness and roundness" for Pinot Meunier (Jackson 2008). A sparkling wine made only from white grapes, and typically Chardonnay, is called a "Blanc de Blancs" and a sparkling wine made only from dark-skinned grapes, typically Pinot noir and/or Pinot Meunier grapes, is called a Blanc de Noirs (Chamkha et al. 2003). Chenin blanc is grown in the Loire Valley of France for sparkling wine production, in particular for its naturally high acidity retention, and also in the Limoux region of France together with the more traditional variety of Mauzac (Robinson 2006).

Pinot noir, Chardonnay, Pinot Meunier, and Pinot blanc are varieties most commonly used for sparkling wine production in California (Zoecklein 2002, de la Presa-Owens et al. 1998), while Chardonnay and Pinot noir are predominantly used in cool-climate regions such as New Zealand (Hancock 1994) and Australia, with the occasional use of Pinot Meunier and Pinot blanc. In hot regions, varieties such as Parellada, Xarelilo, Macabeo, Chenin blanc, and Semillon are also used for sparkling production, and Gamay is used in both warm and cool climates (Dry and Ewart 1985; cited in Zoecklein 2002). Spanish grape varieties Verdejo, Viura (Macabeo), Malvasia, Albarin, Godello, Garnacha, and Prieto Picudo were evaluated for high-quality sparkling wines, and Prieto Picudo, Albarin, and Verdejo were the most promising varieties due to superiority in sensory profiling (Martinez-Lapuente et al. 2013).

In a comparison of Fernão-Pires and Baga varieties, the volatile composition of sparkling wines was more influenced by variety than by soil type or stage of ripening (Coehlo et al. 2009). The more traditional sparkling wine or Champagne varieties of Chardonnay, Pinot blanc, Pinot noir, and Pinot Meunier have been shown to contribute different aroma profiles to base wines (de la Presa-Owens et al. 1998); Chardonnay and Pinot blanc base wines were characterized by floral, citrus, and apple aromas, whereas Pinot noir and Pinot Meunier base wines were characterized by berry and vanilla/ butter aromas. However, the aroma profiles exhibited by the base wines did not enable prediction of the sensory profiles of the sparkling wines after aging on lees for 18 months. Caution must be taken when predicting sparkling wine flavor

\begin{tabular}{|c|c|c|c|c|c|c|}
\hline & \multicolumn{2}{|c|}{ Chardonnay } & \multicolumn{2}{|c|}{ Pinot noir } & \multirow{2}{*}{$\begin{array}{c}\text { Colombard } \\
\text { California } \\
\end{array}$} & \multirow{2}{*}{$\begin{array}{c}\text { Chenin blanc } \\
\text { California } \\
\end{array}$} \\
\hline & California & Australia & California & Australia & & \\
\hline Brix & $18.0-19.0$ & $16.2-21.6$ & $18.0-20.0$ & $18.0-21.6$ & $17.5-20.0$ & $17.5-19.0$ \\
\hline Titratable acid $(\mathrm{g} / \mathrm{L})$ & $11.0-14.0$ & $11.0-16.0$ & $10.0-13.0$ & $11.0-16.0$ & $12.0-14.0$ & $10.0-11.0$ \\
\hline $\mathrm{pH}$ & $2.90-3.15$ & $2.90-3.2$ & $2.90-3.15$ & $2.90-3.2$ & $2.90-3.20$ & $3.10-3.20$ \\
\hline
\end{tabular}


and aroma profiles from base wine flavor and aroma profiles because of the modification of sensory properties by yeast autolysis (Alexandre and Guillox-Benatier 2006) and the amplification of aromas during the secondary in-bottle fermentation (Zoecklein 2002).

Each of the three main grape varieties used for sparkling wine production have different wine maturation rates, with Pinot Meunier the most rapidly maturing variety, Pinot noir intermediate, and Chardonnay the slowest (Thibaut and Parsiot 1994, Jackson 2008). Autolytic development is predominantly determined by yeast strain but is also influenced by other factors such as base wine composition and aging time (Alexandre and Guillox-Benatier 2006).

The different grape varieties also impact foaming properties of sparkling wines (Andres-Lacueva et al. 1997). Marchal et al. (2001) reported that sparkling wines from Pinot noir

\begin{tabular}{|c|c|}
\hline Origin/style & Variety \\
\hline \multicolumn{2}{|l|}{ France } \\
\hline Champagne & $\begin{array}{l}\text { Chardonnay } \\
\text { Pinot noir } \\
\text { Pinot Meunier }\end{array}$ \\
\hline Sparkling wine & $\begin{array}{l}\text { Chenin blanc } \\
\text { Mauzac }\end{array}$ \\
\hline \multicolumn{2}{|l|}{ Germany } \\
\hline Sekt & $\begin{array}{l}\text { Riesling } \\
\text { Silvaner } \\
\text { Pinot blanc } \\
\text { Pinot noir } \\
\text { Pinot gris }\end{array}$ \\
\hline \multicolumn{2}{|l|}{ Italy } \\
\hline Franciacorta & $\begin{array}{l}\text { Chardonnay } \\
\text { Pinot noir } \\
\text { Pinot blanc }\end{array}$ \\
\hline Asti & Muscato bianco \\
\hline Prosecco & Prosecco \\
\hline Lambrusco & $\begin{array}{l}\text { Lambrusco bianco } \\
\text { Lambrusco nero }\end{array}$ \\
\hline Talento & $\begin{array}{l}\text { Chardonnay } \\
\text { Pinot noir } \\
\text { Pinot blanc }\end{array}$ \\
\hline \multicolumn{2}{|l|}{ Spain } \\
\hline Cava & $\begin{array}{l}\text { Macabeo (Viura) } \\
\text { Parellada } \\
\text { Xarel.lo } \\
\text { Garnacha } \\
\text { Chardonnay } \\
\text { Albarin } \\
\text { Godello } \\
\text { Malvasia } \\
\text { Verdejo } \\
\text { Prieto Picudo }\end{array}$ \\
\hline \multicolumn{2}{|c|}{$\begin{array}{l}\text { United States, Australia, } \\
\text { South Africa, New Zealand }\end{array}$} \\
\hline Sparkling wine & $\begin{array}{l}\text { Pinot noir } \\
\text { Chardonnay } \\
\text { Pinot Meunier }\end{array}$ \\
\hline
\end{tabular}

display the greatest foam height, followed by Pinot Meunier, with Chardonnay the lowest, whereas Andres-Lacueva et al. $(1996,1997)$ found Chardonnay cavas led to high foamability and lowest stability time. Blending of different varietal wines improved the foaming properties with respect to each varietal wine separately, owing to a synergistic effect among components (Andres-Lacueva et al. 1996).

\section{Clones}

Clonal evaluations have been reported by research teams worldwide, including Burgundy, Champagne, Australia, Canada, New York, Oregon, and California (Anderson et al. 2008a). Localized studies are valued because of field observation that clonal performance varies in different locations (Cirami and Ewart 1995), presumably affected by mesoclimates and soils.

Notably in France, clonal selection of Pinot noir for sparkling wines has been conducted independently from clonal research on Pinot noir for table wine (Barillere et al. 1995), a fairly unique exception to the general lack of research specific to fruit production for sparkling wine. Sparkling wine producers typically look for Pinot noir clones with higher acidity, higher yield, and lower anthocyanin and tannin content than their table wine counterparts (Barillere et al. 1995, Bernard 1995, Pool et al. 1995). In Champagne, the Chardonnay clones available include 75, 76, 95, 96, and 121 and the Pinot noir clones include 386, 521, 870, and 779 (Coppolani 1994).

In a California vineyard, the viticultural characteristics of 12 Pinot noir clones specifically selected for sparkling wine production in Champagne, France, were compared to eight California clones (Anderson et al. 2008a). Results showed yield and yield components differed widely among clones. Clones were harvested on a soluble solids basis, with a target of 20 Brix. There was a 15-day difference in harvest date on average from first to last clone harvested. Ranges in titratable acidity and $\mathrm{pH}$ values were statistically significant. Unfortunately, measurements of phenolics such as anthocyanins were not made in this study. Vegetative growth, measured as pruning weight, differed more than two-fold among clones. The relative performance of the individual clones also differed in studies conducted in other regions, highlighting that clones perform differently under different conditions. In a second study in California, differences among clones of Pinot noir were reported to be greater than those reported by other researchers for clones of Chardonnay (Mercado-Martin et al. 2006). The study indicates that some clones have potential for high yield and others for excessive vegetative growth. Differences in yield were largely due to cluster weight. In terms of yield, cluster number had a greater affect on Pinot noir than on the other varieties investigated. It is not clear however, whether this difference was due to fruitfulness of nodes retained or differences in numbers of blind buds.

A California study on the performance of six Chardonnay clones in California found that clones differed in yield, cluster size, berries per cluster, and yield to pruning weight ratio (Wolpert et al. 1994). In another California study of 13 Chardonnay clones, two of California origin and 11 of French 
origin, variations in yield, berries per cluster, berry weight, cluster weight, and clusters per shoot were detected when all clones were harvested at $21 \pm 0.5$ Brix (Anderson et al. 2008b). Whether distinct clonal performance between regions is due to climate, soil, rootstock choice, or cultural practices has not been determined. There are clear implications of clonal selection for adequate yields and sugar:acid characters for the production of fruit for sparkling wine, although impacts on fruit quality have largely been overlooked, which is a significant knowledge gap and crucial for production of premium fruit and wine.

\section{Vine Density, Pruning System, Canopy Management, and Harvest Method}

Both vine density and pruning system have been tightly legislated and controlled in Champagne by the INAO (National Institute of Appellation of Origin) since 1938 (Coppolani 1994). The sum of the distance between rows and vines must be less than $2.5 \mathrm{~m}$, which results in a highdensity planting in the order of 8000 vines per hectare. Champagne has a high annual rainfall, resulting in soil water availability to vines throughout the year, which is prejudicial to maturity (Coppolani 1994). The high planting density is thought to stimulate root competition for water and other nutrients and assists fruit in reaching adequate maturity by reducing vegetative growth (Coppolani 1994); however, studies supporting this speculation could not be found. According to Reynolds et al. (2004), the view that closely spaced grapevines are necessary for high-quality wine is a widespread misconception, and results showed minimal impact of vine spacing on yield and fruit composition under situations where soil conditions were not limiting. For vines grown in more fertile soils, a high-density planting may result in reduced density of buds and an increase in the proportion of secondary buds bursting, both factors having an impact on the rate of ripening.

Hancock (1994) states that planting distances and row orientation, trellis training, and pruning are all important considerations for quality sparkling wine production, in that they control fruit exposure and vigor which impact on fruit flavors and acid balance. However, no such standard practice for planting density occurs for sparkling production in New World countries such as Australia. In Champagne, the height of buds from ground level at pruning should not be greater than $0.6 \mathrm{~m}$ to limit the canopy height to $\sim 1.3 \mathrm{~m}$, thus limiting the degree of interrow shading (Coppolani 1994), but that would be a function of row width. The permitted pruning systems in Champagne are Chablis, Royat, Guyot, and Vallée de la Marne; however, only the Chablis and Royat systems are permitted for Champagne Grands Crus (Coppolani 1994). New World sparkling wine vineyards commonly use vertical shoot-positioning (VSP) for ease of management or a Scott Henry trellis, which has the advantage of being adaptable for either cane- or spur-pruning.

In a study with Barbera, researchers concluded that similar crop potential and quality expression can be achieved in either cane- or spur-pruned training systems when properly managed (Bernizzoni et al. 2009). Results indicated that vine spacing had no effect on Barbera grape composition, when interrow spacing varied between 0.9 and $1.5 \mathrm{~m}$, across VSP spur-pruned low cordon, single high-wire cordon, single Guyot, and vertically split double Guyot. In the same trial, must composition at harvest was similar among VSP spurpruned low cordon, single high-wire cordon, and single Guyot, while vertically split double Guyot produced grapes of overall inferior quality; no significant differences were found in yield per vine across training systems. The inferior quality of split double Guyot was thought to be due to a somewhat delayed ripening. The SPC fruit was of a significantly higher $\mathrm{pH}$ and lower titratable acidity, suggesting that it would be less desirable for sparkling wine production than the other training systems. Bernizzoni et al. (2009) advised that vine spacing at $0.9 \mathrm{~m}$ within-row was preferable, as it ensures a $20 \%$ higher yield per hectare of comparable grape quality across training systems, although disease pressure could be a consideration with planting density on relatively high humidity sites.

In a comparison of four training systems for production of Pinot noir for table wine in Italy (simple Guyot, double Guyot, horizontal spurred cordon, vertical spurred cordon), yields ranged among systems from 7.5 to 9.7 tonnes/ha, but training system had little or no impact on grape or wine composition, with sensory analysis showing no difference among systems (Peterlunger et al. 2002). The simple Guyot system resulted in a higher $\mathrm{pH}$ and a lower titratable acidity and the double Guyot also resulted in a lower titratable acidity, suggesting these two systems would perhaps be less desirable for sparkling wine production than the other training systems. Van Zyl and van Huyssteen (1980) found that microclimate differences among four training systems in Chenin blanc vines had no effect on fruit composition. These studies indicate that, with the appropriate training system, yield can be increased with no detrimental impact on fruit quality for these varieties that are commonly used in sparkling wine production (Reynolds and Vanden Heuvel 2009).

With a rise in the use of mechanical pruning, trials comparing the fruit and wine quality from spur- and canepruned vines are becoming more common; however, to date studies have focused on table wine rather than sparkling wine. Jackson and Lombard (1993) reported that Pinot noir aroma was reduced when vines were spur-pruned, despite yield and maturation similar to cane-pruned vines. A study that compared Chardonnay vines under traditional Royat trellis with vines mechanically pruned showed that mechanically pruned vines had a higher number of smaller clusters than did Royat trellis (Goma-Fortin et al. 2013). Tasters noted mechanically pruned vines had more intense fruit flavors and quality aromas. It is possible that the increased intensity of aroma and fruit flavors was a result of the smaller berry size under mechanized pruning. Poni et al. (2004) demonstrated that short mechanical hedging can be successfully applied even on cultivars with low fruitfulness of basal buds, showing no detriment to grape quality and a decrease in labor demand by 55 to $60 \%$. 
Canopy management in the form of different trellising options can be used to manipulate key berry attributes at harvest. Pinot noir berry phenolics were increased by divided canopies, including Scott Henry, lyre, and Geneva double curtain, over undivided up-right shoot canopies, but the wines from undivided canopies had more typical fruit flavor and aroma (Jackson and Lombard 1993). Studies by Smart and colleagues suggest that a shaded microclimate increases the $\mathrm{pH}$ and potassium $(\mathrm{K})$ content of the must and reduces both wine color and content of phenolic compounds (Smart 1984, Jackson and Lombard 1993).

A common method to increase light incidence on berries is to remove leaves, predominantly in the fruiting zone. This method can lead to faster grape maturation measured by increased sugar concentration at harvest (Reynolds et al. 2007), can have no significant effect (Percival et al. 1994, Tardaguila et al. 2010), or can decrease sugar concentration due to limitation of photosynthates (Iacono et al. 1995, Koblet et al. 1995). Similarly variable responses of berry $\mathrm{pH}$ and TA to leaf removal have been reported (Koblet et al. 1995, Percival et al. 1994, Reynolds et al. 2007), highlighting the need for local, variety-specific investigations into the practice to determine suitability of this management practice to meet the fruit quality goals for sparkling wine production.

Removal of different quantities of leaves as they appeared on Pinot noir vines resulted in slower initial berry growth and final size and a delay in veraison in one study (Petrie et al. 2000). The authors reported soluble solids and total sugar content increased more rapidly when more leaves were retained, and final soluble solids and sugar content at harvest were decreased by all degrees of leaf removal. Shade, whether natural or artificial, typically reduces sugar levels and usually increases acidity on any one date, a response normally interpreted as delayed maturity (Reynolds et al. 1985). For this reason, it is possible that a degree of shading may be beneficial for sparkling wine production.

Hydroxycinnamates are known to impact texture and mouthfeel of sparkling wines (Kerslake et al. 2013). Changes in cluster exposure as a result of leaf removal led to differences in UV absorbance of juice samples at 310 and $330 \mathrm{~nm}$ (Kerslake et al. 2013), wavelengths that are indicative of hydroxycinnamates (Verette et al. 1988). Results suggest that there was a significant decrease in hydroxycinnamates in Pinot noir and Chardonnay base wines when leaf removal occurred. An increase in light exposure due to leaf removal is a possible explanation for the differences, and in one study berries with increased light exposure had decreased levels of hydroxycinnamic acids (Kolb et al. 2003).

Leaf removal, when performed sufficiently early, has been shown to have beneficial effects on cluster morphology and the resulting fruit composition. In Barbera, early leaf removal led to looser clusters and improved quality traits, especially increased soluble solids and color (Poni et al. 2005); similar results were seen with Graciano and Carignan (Tardaguila et al. 2010). In a study by Sabbatini and Howell (2010), early defoliation did not significantly affect any parameters measured, revealing only a slight decrease in cluster weight for Pinot noir. The difference in cluster size between the varieties of the two studies could explain the different results. Graciano and Carignan are both very large clustered varieties, whereas Pinot noir, Pinot gris, and Vignoles are small clustered (Sabbatini and Howell 2010).

In order to achieve the highest quality sparkling wine, traditional "late" (preveraison) leaf removal should be avoided, as it usually permanently overexposes clusters and leads to an undesirable decrease in malic acid. "Early" (i.e., flowering) leaf removal does not seem to lead to overexposure, since the season is long enough to cast some shade on the clusters, while Poni et al. (2005) found that an early leaf removal promotes tartaric acid. The decision about early season leaf removal needs to consider the cost involved and the potential improvement in the resulting wine quality.

The composition of juice will also be affected by harvesting method, which in Champagne is limited to hand harvesting only (Coppolani 1994). Machine harvesting of fruit has been reported to damage berries, which can result in juice oxidation (Hancock 1994). The time and extent of skin contact of machine-harvested fruit will also impact fruit and juice quality; however, this observation is anecdotal. The size of the picking containers can impact fruit integrity (Hancock 1994); again another parameter regulated in Champagne to the use of small bins with holes (Coppolani 1994). Pocock and Waters (1998) showed that despite a greater extent of juice oxidation occurring in mechanically harvested fruit compared with hand-harvested fruit, the greater level of oxidation had little effect on the protein content of the wine, suggesting that mechanical harvesting of fruit will not have adverse effects on sparkling wine quality when appropriate winemaking techniques are used.

\section{Climate and Soil Factors}

As noted earlier, vineyard location has been described as one of the key factors influencing the character of bottlefermented sparkling wines (de La Presa-Owens et al. 1998). Climate has been attributed as the most important factor affecting quality in Champagne (Thibaut and Parsiot 1994). Incidences of adverse weather conditions during the growing season, in particular later in the season, can have disastrous results for wine quality. For example, rainfall prior to harvest can lead to fungal infection in the fruit (Soar et al. 2008). Such concerns highlight the need for flexible viticultural management programs for successful sparkling wine production, particularly in cool and variable climates.

In managing vines for sparkling production, the effects of local climatic patterns, both seasonal and diurnal, on basic juice composition should be considered. Several studies have shown that sugar accumulation is influenced by temperature in the first two phases of berry growth (stages I and II) but that temperature has little effect on final sugar levels in the final berry growth phase (stage III) (Buttrose et al. 1971, Hale and Buttrose 1974). In contrast, another study found that sugar was related to temperatures in stage III (Hofäcker et al. 1976). Cool nights associated with warm day temperatures led to lower $\mathrm{pH}$ and higher acidity at harvest compared 
with warm days and warm nights (Kliewer 1973). A general guideline is the warmer the sparkling wine producing region, the earlier the grapes need to be harvested to ensure low $\mathrm{pH}$ and high acidity levels, as sparkling wines with higher $\mathrm{pH}$ and lower acidity levels tend to develop more quickly and are more likely to display more overt fruit flavors and less complexity (Zoecklein 2002). Variation in total phenolic content of Pinot noir and Chardonnay Champagnes was found to be a function of the vintage; researchers concluded that abundant rain in 2001 diluted flavor compounds relative to the 2000 vintage (Chamkha et al. 2003).

Soil type, and in particular physical aspects including depth and texture, will greatly affect vine vigor (Hancock 1994). In a study of the table wine varieties Merlot, Cabernet Sauvignon, and Cabernet franc, soil type was a major influence on berry weight and as important a factor as cultivar for explaining variation in berry sugar and anthocyanin concentration (Van Leeuwen et al. 2004). Soil type was less important for total acidity and $\mathrm{pH}$ of the grape juice. There is a strong relationship between improved grape quality and water deficit before veraison, when water deficit probably affects grape quality indirectly. The study by van Leeuwen et al. (2004) showed that an early water deficit induced early shoot growth cessation and reduced berry size. Under these conditions, berry sugar and anthocyanin concentrations increase because of more rapid ripening. The authors concluded that the effects of soil on vine development and berry composition can be explained largely by their influence on vine water status. Similarly, Coelho et al. (2009) compared sparkling wines made from grapes produced in three types of soil and concluded that soil type impacted on wine quality. The clay-calcareous and clay soils that had good water-holding and drainage capacity produced wines richer in volatiles than wines produced from fruit grown on sandy soils. Based on a New Zealand study, the authors suggest that physical characteristics of different soil types should be considered relevant at least because of their apparent effect on soil temperature and soil moisture content, which in turn impact vine growth and resulting wine quality (Tesic et al. 2002). A greater degree of flexibility in the required soil attributes and the resulting influence on vine water status exists for sparkling wine production than for table wine varieties such as the Bordeaux varieties examined in the work of van Leeuwen et al. (2004), due to the lower sugar concentration required at harvest.

\section{Yield}

Yields in Champagne are prescribed by the Appellation d'Origine Contrôlée, so if predictions exceed permitted yields, fruit removal is necessary before harvest (Coppolani 1994). A similar regulation exists in Spain for the production of cava (Pozo-Bayon et al. 2004). There is a lack of research specifically with sparkling wines to support the notion that lower yields lead to higher quality, and it is quite possible that if the crop level is too low, the fruit may become overripe, especially in warm seasons. In some regions the decision to limit yield may not be related to fruit quality, but rather to limit wine production and retain higher prices. In other cool-climate sparkling wine production regions, such as New Zealand, crop level is managed in order to improve fruit flavor intensity (Hancock 1994) by manipulating vine balance. In Australia, while evidence is based on commercial experience, higher yields (for example up to 16 tonnes/ha using a VSP system on a fertile site) are more accepted for sparkling wine production than for table wine production; however, these yields are not regulated and price is set using quality perceived by winemakers. The ideal cropping level may be dependent on the desired style of sparkling wine, with some producers preferring high-acid, less fruit-driven styles.

Winter pruning is the first opportunity to manipulate yield. A primary aim when choosing bud number per vine is to achieve balance between vegetative and fruit growth while simultaneously providing appropriate fruit composition for winemaking (Jackson and Lombard 1993, Tassie and Freeman 2004). The exposed leaf area to fruit ratio affects the rate of maturation of the fruit, which will in turn influence grape and wine quality (Zoecklein 2002). Pruning as a method of yield regulation will also assist in control of vigor and influence fruit exposure, fruit flavors, and acid balance later in the season (Hancock 1994). In Champagne, vines are not pruned too early in the attempt to avoid early budburst and possible spring frost damage (Coppolani 1994). The link between later pruning and later budburst is supported on a study in which delaying pruning by six weeks delayed budburst, and maturity by approximately five days (Martin and Dunn 2000). Thus, pruning time may be an important factor to consider in planning vineyard operations for sparkling wine production.

Recommendations in Champagne are that fruit removal around veraison is ideal and that removal of $30 \%$ of the fruit will result in a less than $0.5 \%$ increase in potential alcohol, whereas removing from 30 to $50 \%$ could increase potential alcohol between 0.5 and 1.5\% (Coppolani 1994). However, fruit removal is a costly exercise and it is yet to be economically proven that crop load reduction at veraison produces a significant enough increase in fruit and sparkling wine quality to justify the cost. A trial with Chardonnay for table wine found that the cost of cluster removal outweighed the fruit quality benefits (Reynolds et al. 2007), and similar results were found for Riesling, where the substantial increases in fruit price necessary to offset from the costs of cluster removal were not warranted (Preszler et al. 2013). Research into the effects of cluster thinning on fruit quality and the cost:benefit analysis for fruit destined for sparkling wines is needed.

In a study with the Parellada variety, the concentrations of most phenolic compounds were higher in sparkling wines (cavas) produced with grapes from high yielding vineyards than those produced from a low yielding vineyard (PozoBayon et al. 2004). No information was given regarding the vine characteristics, management practices, or environmental conditions of the different vineyards, making it difficult to interpret the results. It is possible that the higher yielding vines were grown on more fertile soils, allowing for a 
larger crop to be ripened and a greater degree of phenolic development. There were no significant differences between the foam characteristics of the wines from different yielding vineyards. Overall, the tasters preferred wines from grapes grown in low yielding vineyards based on sensory quality over the wines from high yielding vineyards, despite the lower phenolic concentrations in wines from low yielding vineyards. In another study with Parellada, there were differences in composition between cava wines from low and high yielding vineyards (Riu-Aumatell et al. 2002). Both TA and $\mathrm{pH}$ were significantly higher in fruit from high yielding vineyards. However, the maturation index, the ratio between total soluble solids and titratable acidity, which represents a balance between sugar and acid (Gris et al. 2010), did not vary significantly, suggesting that although the acidity was lower in grapes from low yielding vineyards, they were not riper.

Increased crop level in production of grapes for table wine has been shown to delay maturity in grapevines by resulting in lower fruit composition parameters at harvest, such as sugar (total soluble solids) and titratable acidity (Winkler 1970). A study of Pinot noir found that increasing nodes retained at pruning, from 20 nodes per vine to 30 nodes per vine, resulted in a significant drop in $\mathrm{pH}$, and a significant positive regression between $\mathrm{pH}$ and total soluble solids, regardless of the number of nodes retained, when nodes varied between 10 and 40 (Heazlewood et al. 2006). A study in New Zealand found that by increasing the number of nodes retained at winter pruning, yield increased 3.5-fold in Chardonnay and other varieties, with little effect on the basic fruit composition parameters of total soluble solids, $\mathrm{pH}$, and titratable acidity (Jackson and Steans 1983-4, Jackson et al. 1984), contrary to the findings of the Heazlewood et al. (2006) trial.

Yield of winegrapes will modify fruit composition in two ways: first by intrinsic changes that are directly due to yield, including soluble solids, organic acids, $\mathrm{pH}$, phenolics, and anthocyanins, and second by changing the rate of ripening (Jackson and Lombard 1993). Because high yields (to the point of overcropping) delay maturity (Winkler 1954), direct effects are not always easy to measure, since they require grapes to be harvested at equivalent maturity.

Studies of crop removal have shown that soluble solids will increase after thinning until a specific crop level is attained, below which little effect will occur. Low crop levels will possibly also increase $\mathrm{pH}$ and lower TA, increase anthocyanins and aromatic constituents such as volatile terpenes, and enhance perceived wine quality (Jackson and Lombard 1993). In a trial examining the effects of cluster thinning and leaf removal, Pinot noir wines had higher phenolic levels when vines were subjected to cluster thinning treatments at veraison than when subjected to leaf removal treatments (Mazza et al. 1999). Cluster thinning at bloom also resulted in higher phenolics. Cluster thinning has been shown to increase total anthocyanins and total phenolics (Jackson and Lombard 1993, Prajitna et al. 2007). For Grenache, highintensity mechanical thinning led to an increase in soluble solids by 3 Brix as well as a decrease in titratable acidity and an increase in $\mathrm{pH}$; no effect was observed in Tempranillo (Diego et al. 2010). Clearly the principles developed around yield manipulation for table wine fruit production have the potential to be applied and further developed with respect to fruit production specifically for sparkling wines, and trials should be run in different regions. However, the studies reported here demonstrate an increase in sugar, decrease in titratable acidity, and increase in $\mathrm{pH}$ as a result of cluster removal, suggesting that the practice may be detrimental to sparkling wine quality.

\section{Impact of Climate Change and Possible Techniques for Mitigation}

The changing climate is having a profound impact on sparkling wine production worldwide. Increased temperature and changes in precipitation patterns could impact on grape production either positively or negatively, depending on the present climate of a region. The projected rate of warming is not consistent among regions, so too the projected precipitation, as some regions will become drier and others wetter (Webb et al. 2013). For most regions over the summer period, median model results indicate a drying of the climate. Winter precipitation is projected to increase slightly for the more northern European locations, North American regions, and New Zealand. For Australian sites, southern European regions, and South Africa, a likely reduction in winter precipitation is projected (Webb et al. 2013).

A growing body of evidence indicates that as climates warm, winegrape phenology progresses more rapidly and grapes ripen earlier (Webb et al. 2011). As fruit composition is strongly influenced by temperature, with higher temperature increasing the speed of sugar accumulation, hastening acid degradation, and altering flavor compounds (Webb et al. 2013), sparkling wine quality could be compromised in the future in some regions currently focused on sparkling wine production. Elevated temperature has been shown to decouple anthocyanins and sugars in berries of red wine varieties, which has consequences for the color:alcohol balance in the finished wine (Sadras and Moran 2012) and may lead to higher alcohol content, an issue with relevance for sparkling wines.

Growers are faced with decisions about which varieties will be best suited to sparkling wine production in a future warmer environment and with developing techniques to help manage faster ripening and changes in fruit composition. Introducing flexibility into the traditional regulatory systems in France, Italy, and Germany may be necessary to allow for changes to permitted varieties in those regions and for changes in management, such as the introduction of irrigation. It is also likely that viticulture for sparkling wine may move into new regions, such as those currently considered too cool for viticulture, including areas of southern Australia, North and South America, and England.

It is possible that vineyard management techniques may be applied to mitigate some of the negative impacts of increased speed of ripening. Palliotti et al. (2013b) showed that mechanical leaf removal postveraison on Sangiovese vines, apical to the fruiting zone, is a practical strategy to delay sugar 
accumulation in the berry by approximately two weeks as compared with non-defoliated vines. The application of the film-forming antitranspirant Vapor Gard postveraison above the cluster zone was also shown to be an effective, simple technique to slow berry sugar accumulation (Palliotti et al. 2013a).

\section{Conclusion}

Clearly fruit quality goals are distinct for sparkling wine versus table wine, yet remarkably similar across international growing regions. In France and some regions of Spain, the viticulture for producing Champagne and cava is predominantly prescribed by the region, with aspects of varietal use, grapegrowing, wine production, and maturation regulated by authorities, whereas other sparkling wine producing regions, such as Australia, may have no legal regulation. The relatively low management input applied specifically for grapes destined for sparkling wines as compared to table wines in wine-producing regions throughout the world is clear.

This review has highlighted differences in vegetative growth, yield, and fruit composition of varieties and clones grown in difference regions, clearly necessitating distinct viticultural management between regions given the relatively uniform objectives for fruit quality across regions. Yield and effects of crop load management and leaf removal can improve fruit quality for table wine production, but equally these practices can be ineffective or even detrimental, depending on the vintage and variety. There is minimal research on viticultural practices that arrive at the desirable attributes of fruit for sparkling wine, including a lower $\mathrm{pH}$, higher titratable acidity, and a lower Brix than for table wines. There is a need for research on the effect of increasing the temperature and changes in the light environment around clusters that are specifically grown for sparkling wine production and a need to test the interaction of local terroir with viticultural management techniques, such as cluster thinning, on fruit quality and sparkling wine.

The mechanization of pruning, canopy management, crop load manipulation, and harvest is expected to increase in the future, due to its ability to reduce labor costs considerably. Coupled with the ability to slow the rate of grape ripening by manipulating the vine canopy, the choice of training system in the future may be primarily based on establishment and management costs, the latter including different degrees of mechanization. Research into producing optimal fruit quality in systems designed to accommodate mechanization is warranted.

Finally, there is the critical issue of climate warming, which may compromise the production of fruit for premium sparkling wine, with respect to maintaining flavor development and high acidity. Warming presents a significant challenge to fruit production given the documented effects of temperature increase on ripening and loss of acidity. The current, and likely future, move to alternative varieties and clones will require increased research effort, as will movement of production to cooler regions, which are associated with additional challenges such as late frost and increased disease pressure.

\section{Literature Cited}

Alexandre, H., and M. Guilloux-Benatier. 2006. Yeast autolysis in sparkling wine - A review. Aust. J. Grape Wine Res. 12:119-127.

Anderson, M.M., R.J. Smith, M.A.Williams, and J.A. Wolpert. 2008a. Viticultural evaluation of French and California Pinot noir clones grown for production of sparkling wine. Am. J. Enol. Vitic. 59:188-193.

Anderson, M.M., R.J. Smith, M.A. Williams, and J.A. Wolpert. $2008 \mathrm{~b}$. Viticultural evaluation of French and California Chardonnay clones grown for production of sparkling wine. Am. J. Enol. Vitic. 59:73-77.

Andres-Lacueva, C., M. Gallart, E. Lopez-Tamames, and R.M. Lamuela-Raventos. 1996. Influence of variety and aging on foaming properties of sparkling wine (cava). 1. J. Agric. Food Chem. 44:38263829.

Andres-Lacueva, C., R.M. Lamuela-Raventos, S. Buxaderas, and M. del Carmen de la Torre-Boronat. 1997. Influence of variety and aging on foaming properties of cava (sparkling wine). 2. J. Agric. Food Chem. 45:2520-2525.

Barillere, J.M., A. Collas, C. Bougerey, and C. Palgé. 1995. Clonal selection in Champagne. In Proceedings of the International Symposium on Clonal Selection. J.A. Wolpert et al. (eds.), pp. 33-39. Am. Society for Enology and Viticulture, Davis.

Bernard, R. 1995. Aspects of clonal selection in Burgundy. In Proceedings of the International Symposium on Clonal Selection. J.A. Wolpert et al. (eds.), pp. 17-19. Am. Society for Enology and Viticulture, Davis.

Bernizzoni, F., M. Gatti, S. Civardi, and S. Poni. 2009. Long term performance of Barbera grown under different training systems and within-row vine spacings. Am. J. Enol. Vitic. 60:339-348.

Buttrose, M.S., C.R. Hale, and W.M. Kliewer. 1971. Effect of temperature on the composition of 'Cabernet Sauvignon' berries. Am. J. Enol. Vitic. 22:71-75.

Chamkha, M., B. Cathala, V. Cheynier, and R. Douillard. 2003. Phenolic composition of Champagnes from Chardonnay and Pinot Noir vintages. J. Agric. Food Chem. 51:3179-3184.

Cirami, R.M., and A.J.W. Ewart. 1995. Clonal selection, evaluation, and multiplication in Australia. In Proceedings of the International Symposium on Clonal Selection. J.A. Wolpert et al. (eds.), pp. 52-59. Am. Society for Enology and Viticulture, Davis.

Coelho, E., M.A. Coimbra, J.M.F. Nogueira, and S.A. Rocha. 2009. Quantification approach for assessment of sparkling wine volatiles from different soils, ripening stages, and varieties by stir bar sorptive extraction with liquid desorption. Anal. Chim. Acta 635:214-221.

Coppolani, C. 1994. Viticulture relating to sparkling wine. In Proceedings of Sparkling Wine and Quality Management. A. Markides and R. Gibson (eds.), pp. 9-15. Aust. Society of Viticulture and Oenology, Adelaide.

de La Presa-Owens, C., P. Schlich, H.D. Davies, and A.C. Noble. 1998. Effect of Mèthode Champenoise process on aroma of four $V$. vinifera varieties. Am. J. Enol. Vitic. 49:289-294.

Diago, M.P., M. Vilanova, J.A. Blanco, and J. Tardaguila. 2010. Effects of mechanical thinning on fruit and wine composition and sensory attributes of Grenache and Tempranillo varieties (Vitis vinifera L.). Aust. J. Grape Wine Res. 16:314-326.

Gris, E.F., V.M. Burin, E. Brighenti, H. Vieira, and M.T. BordignonLuiz. 2010. Phenology and ripening of Vitis vinifera L. grape varieties in Sao Joaquim, southern Brazil: A new South American wine growing region. Cien. Inv. Agri. 37:61-75.

Goma-Fortin, N., E. Lebon, and W. Trambouze. 2013. Transformation of the pruning system: From a Royat trellis system to a precise mechanical pruning system. Effects on the agronomic characteristics. In $18^{\text {th }}$ International Symposium GiESCO-Proceedings. J. Queiróz and A. Carneiro (eds.), pp. 671-676. University of Porto, Portugal. 
Hale, C.R., and M.S. Buttrose. 1974. Effect of temperature on ontogeny of berries of Vitis vinifera cv. Cabernet Sauvignon. J. Am. Hortic. Sci. 99:390-394.

Hancock, J. 1994. Complexing factors in sparkling wine, with particular reference to New Zealand. In Proceedings of Sparkling Wine and Quality Management. A. Markides and R. Gibson (eds.), pp. 16-18. Aust. Society of Viticulture and Oenology, Adelaide.

Heazlewood, J.E., S. Wilson, R.J. Clark, and A.J. Gracie. 2006. Pruning effects on Pinot Noir vines in Tasmania (Australia). Vitis 45:165-171.

Hofâcker, W., G. Alleweldt, and S. Khader. 1976. Einfluss von Umweltfaktoren auf Beerenwachstum und Mostqualitât bei der Rebe. Vitis 15:96-112.

Iacono, F., M. Bertamini, A. Scienza, and B.G. Coombe. 1995. Differential effects of canopy manipulation and shading of Vitis vinifera $\mathrm{L}$. cv. Cabernet Sauvignon. Leaf gas exchange, photosynthetic electron transport rate and sugar accumulation in berries. Vitis 34:201-206.

Jackson, R.S. 2008. Wine Science: Principles and Applications. Academic Press, San Diego.

Jackson, D.I., and G. Steans. 1983-1984. Optimum bud numbers depend on variety. Southern Hort., Grapegrower Winemaker 1:75-77.

Jackson, D.I., G.F. Steans, and P.C. Hemmings. 1984. Vine response to increased node numbers. Am. J. Enol. Vitic. 35:161-163.

Jackson, D.I., and P.B. Lombard. 1993. Environmental and management practices affecting grape composition and wine quality - A review. Am. J. Enol. Vitic. 44:409-430.

Kerslake, F.L., J.E. Jones, D.C. Close, and R.G. Dambergs. 2013. Bunch exposure effects on the quality of Pinot Noir and Chardonnay fruit and base wines for cool climate sparkling wine production. In $18^{\text {th }}$ International Symposium GiESCO-Proceedings. J. Queiróz and A. Carneiro (eds.), pp. 471-477. University of Porto, Portugal.

Kliewer, W.M. 1973. Berry composition of Vitis vinifera cultivars as influenced by photo-and nycto-temperatures during maturation. J. Am. Soc. Hortic. Sci. 98:153-159.

Koblet, W., M. Keller, and M.C. Candolfi-Vasconcelos. 1995. Effects of training system, canopy management practices, crop load and rootstock on grapevine photosynthesis. Acta Hort. 427:133-140.

Kolb, C.A., J. Kopecký, M. Riederer, and E.E. Pfündel. 2003. UV screening by phenolics in berries of grapevine (Vitis vinifera). Funct. Plant Biol. 30:1177-1186.

Marchal, R., I. Tabary, M. Valade, D. Moncomble, L. Viaux, B. Robillard, and P. Jeandet. 2001. Effects of Botrytis cinerea infection on Champagne wine foaming properties. J. Sci. Food Agric. 90:13711378.

Martin, S.R., and G.M. Dunn. 2000. Effect of pruning time and hydrogen cyanamide on budburst and subsequent phenology of Vitis vinifera L. variety Cabernet Sauvignon in central Victoria. Aust. J. Grape Wine Res. 6:31-39.

Martínez-Lapuente, L., Z. Guadalupe, B. Ayestarán, M. Ortega-Heras, and S. Pérez-Magariño. 2013. Sparkling wines produced from alternative varieties: Sensory attributes and evolution of phenolics during winemaking and aging. Am. J. Enol. Vitic. 64:39-49.

Mazza, G., L. Fukumoto, P. Delaquis, B. Girard, and B. Ewert. 1999. Anthocyanins, phenolics, and color of Cabernet Franc, Merlot, and Pinot Noir wines from British Columbia. J. Agric. Food Chem. 47:4009-4017.

McKenzie, I. 1994. Australian sparkling wine: Style definition. In Sparkling Wine and Quality Management. A Markides and R. Gibson (eds.), p. 4. Aust. Society of Viticulture and Oenology, Adelaide.

Mercado-Martín, G.I., J.A. Wolpert, and R.J. Smith. 2006. Viticultural evaluation of eleven clones and two field selections of Pinot noir grown for production of sparkling wine in Los Carneros, California. Am. J. Enol. Vitic. 57:371-376.
Palliotti, A., F. Panara, F. Famiani, P. Sabbatini, G.S. Howell, O. Silvestroni, and S. Poni. 2013a. Postveraison application of antitanspirant di-1- $p$-menthene to control sugar accumulation in Sangiovese grapevines. Am. J. Enol. Vitic. 64:378-385.

Palliotti, A., F. Panara, O. Silvestroni, V. Lanari, P. Sabbatini, G.S. Howell, M. Gatti, and S. Poni. 2013b. Influence of mechanical postveraison leaf removal apical to the cluster zone on delay of fruit ripening in Sangiovese (Vitis vinifera L.) grapevines. Aust. J. Grape Wine Res. 19:369-377.

Percival, D.C., K.H. Fisher, and J.A. Sullivan. 1994. Use of fruit zone leaf removal with Vitis vinifera L. cv. Riesling grapevines. II. Effect on fruit composition, yield, and occurrence of bunch rot (Botrytis cinerea Pers.:Fr.). Am. J. Enol. Vitic. 45:133-140.

Peterlunger, E., E. Celotti, G. Da Dalt, S. Stefanelli, G. Gollino, and R. Zironi. 2002. Effect of training system on Pinot noir grape and wine composition. Am. J. Enol. Vitic. 53:14-18.

Petrie, P.R., M.C.T. Trought, and G.S. Howell. 2000. Fruit composition and ripening of Pinot Noir (Vitis vinifera L.) in relation to leaf area. Aust. J. Grape Wine Res. 6:46-51.

Pocock, K.F., and E.J. Waters. 1998. The effect of mechanical harvesting and transport of grapes, and juice oxidation, on the protein stability of wines. Aust. J. Grape Wine Res. 4:136-139.

Poni, S., F. Bernizzoni, G. Briola, and A. Cenni. 2005. Effects of early leaf removal on cluster morphology, shoot efficiency and grape quality in two Vitis vinifera cultivars. Acta Hort. 689:217-225.

Poni, S., F. Bernizzoni, P. Presutto, and B. Rebucci. 2004. Performance of Croatina under short-cane mechanical hedging: A successful case of adaptation. Am. J. Enol. Vitic. 55:379-388.

Pool, R.M., T. Henick-Kling, G.E. Howard, B.K. Gavitt, and T.J. Johnson. 1995. Pinot noir clonal research in New York. In Proceedings of the International Symposium on Clonal Selection. J.A. Wolpert et al. (eds.), pp. 45-51. Am. Society for Enology and Viticulture, Davis.

Pozo-Bayon, M.A., M.C. Polo, P.J. Martin-Alvarez, and E. Pueyo. 2004. Effect of vineyard yield on the composition of sparkling wines produced from the grape cultivar Parellada. Food Chem. 86:413-419.

Prajitna, A., I.E. Dami, T.E. Steiner, D.C. Ferree, J.C. Scheerens, and S.J. Schwartz. 2007. Influence of cluster thinning on phenolic composition, resveratrol, and antioxidant capacity in Chambourcin wine. Am. J. Enol. Vitic. 58:346-350.

Preszler, T., T.M. Schmit, and J.E. Vanden Heuvel. 2013. Cluster thinning reduces the economic sustainability of Riesling production. Am. J. Enol. Vitic. 64:333-341.

Reynolds, A.G., and J.E. Vanden Heuvel. 2009. Influence of grapevine training systems on vine growth and fruit composition: A review. Am. J. Enol. Vitic. 60:251-268.

Reynolds, A.G., R.M. Pool, and L.R. Mattick. 1985. Influence of cluster exposure on fruit composition and wine quality of Seyval blanc grapes. Vitis 25:85-95.

Reynolds, A.G., J. Schlosser, R. Power, R. Roberts, J. Willwerth, and C. de Savigny. 2007. Magnitude and interaction of viticultural and enological effects. I. Impact of canopy management and yeast strain on sensory and chemical composition of Chardonnay Musqué. Am. J. Enol. Vitic. 58:12-24.

Reynolds, A.G., D.A. Wardle, M.A. Cliff, and M. King. 2004. Impact of training system and vine spacing on vine performance, berry composition, and wine sensory attributes of Riesling. Am. J. Enol. Vitic. 55:96-103.

Riu-Aumatell, M., M. Lopez-Barajas, E. Lopez-Tamames, and S. Buxaderas. 2002. Influence of yield and maturation index on polysaccharides and other compounds of grape juice. J. Agric. Food Chem. 50:4604-4607.

Robinson, J.B. 2006. The Oxford Companion to Wine. Oxford University Press, Oxford. 
Sabbatini, P., and G.S. Howell. 2010. Effects of early defoliation on yield, fruit composition and harvest season cluster rot complex of grapevines. HortScience 45:1804-1808.

Sadras, V.O., and M.A. Moran. 2012. Elevated temperature decouples anthocyanins and sugars in berries of Shiraz and Cabernet Franc. Aust. J. Grape Wine Res. 18:115-122.

Smart, R.E. 1984. Canopy microclimates and effects on wine quality. In Advances in Viticulture and Oenology for Economic Gain. Proceedings of the Fifth Australian Wine Industry Technical Conference. T.H. Lee and T.C. Somers. (eds.), pp. 113-132. Australian Wine Research Institute, Glen Osmond.

Soar, C., V. Sadras, and P. Petrie. 2008. Climate drivers of red wine quality in four contrasting Australian wine regions. Aust. J. Grape Wine Res. 14:78-90.

Tardaguila, J., F. Martinez de Toda, S. Poni, and M.P. Diago. 2010. Impact of early leaf removal on yield and fruit and wine composition of Vitis vinifera L. Graciano and Carignan. Am. J. Enol. Vitic. 61:372-381.

Tassie, E., and B.M. Freeman. 2004. Pruning. In Viticulture. Vol. 2: Practices. B. Coombe and P.R. Dry (eds.), pp. 66-84. Winetitles, Adelaide.

Tesic, D., D.J. Woolley, E.W. Hewett, and D.J. Martin. 2002. Environmental effects on cv Cabernet Sauvignon (Vitis vinifera L.) grown in Hawke's Bay, New Zealand. 2. Development of a site index. Aust. J. Grape Wine Res. 8:27-35.

Thibaut, C., and M. Parsiot. 1994. Sparkling wine style definition - A French perspective. In Sparkling Wine and Quality Management. A. Markides and R. Gibson. (eds.), pp. 5-8. Aust. Society of Viticulture and Oenology, Adelaide. van Leeuwen, C., P. Friant, X. Choné, O. Tregoat, S. Koundouras, and D. Dubourdieu. 2004. Influence of climate, soil, and cultivar on terroir. Am. J. Enol. Vitic. 55:207-217.

Van Zyl, J.L., and L. van Huyssteen. 1980. Comparative studies on wine grapes on different trellising systems: II. Microclimate studies, grape composition, and wine quality. S. Afr. J. Enol. Vitic. 1:15-25.

Verette, E.N., A.C. Noble, and T.C. Somers. 1988. Hydroxycinnamates of Vitis vinifera: Sensory assessment in relation to bitterness in white wines. J. Sci. Food. Agric. 45:267-272.

Webb, L.B., P.H. Whetton, and E.W.R. Barlow. 2011. Observed trends in winegrape maturity in Australia. Global Change Biol. 17:2707-2719.

Webb, L.B., I. Watterson, J. Bhend, P.H. Whetton, and E.W.R. Barlow. 2013. Global climate analogues for winegrowing regions in future periods: Projections of temperature and precipitation. Aust. J. Grape Wine Res. 19:331-341.

Winkler, A.J. 1954. Effects of overcropping. Am. J. Enol. Vitic. 5:4-12.

Winkler, A.J. 1970. General Viticulture. University of California Press, Berkeley.

Wolpert, J.A., A.N. Kasimatis, and E. Weber. 1994. Field performance of six Chardonnay clones in the Napa Valley. Am. J. Enol. Vitic. 45:393-400

Zoecklein, B. 2002. A Review of Méthode Champenoise Production. Publication 463-017W. Virginia Cooperative Extension Service, Blacksburg. 